\title{
Closing the circle: is it feasible to rehabilitate reefs with sexually propagated corals?
}

\author{
J. R. Guest $\cdot$ M. V. Baria $\cdot$ E. D. Gomez • \\ A. J. Heyward · A. J. Edwards
}

Received: 23 May 2013/Accepted: 4 December 2013/Published online: 27 December 2013

(C) The Author(s) 2013. This article is published with open access at Springerlink.com

\begin{abstract}
Sexual propagation of corals specifically for reef rehabilitation remains largely experimental. In this study, we refined low technology culture and transplantation approaches and assessed the role of colony size and age, at time of transfer from nursery to reef, on subsequent survival. Larvae from Acropora millepora were reared from gametes and settled on engineered substrates, called coral plug-ins, that were designed to simplify transplantation to areas of degraded reef. Plug-ins, with laboratory spawned and settled coral recruits attached, were maintained in nurseries until they were at least 7 months old before being transplanted to replicate coral limestone outcrops within a marine protected area until they were 31 months old. Survival rates of transplanted corals that
\end{abstract}

Communicated by Biology Editor Dr. Mark Vermeij

Electronic supplementary material The online version of this article (doi:10.1007/s00338-013-1114-1) contains supplementary material, which is available to authorized users.

\section{J. R. Guest $(\bowtie)$}

Centre for Marine Bio-Innovation, The University of New South

Wales, Sydney, NSW 2052, Australia

e-mail: jrguest@gmail.com

\section{J. R. Guest}

Advanced Environmental Biotechnology Centre, Nanyang

Environment and Water Research Institute, Nanyang

Technological University, 1 Cleantech Loop, Cleantech One,

\#06-08, Singapore 637141, Singapore

\section{J. R. Guest · A. J. Edwards}

School of Biology, Newcastle University,

Newcastle upon Tyne NE17RU, UK

M. V. Baria · E. D. Gomez

Marine Science Institute, University of the Philippines Diliman,

1101 Quezon City, Philippines remained at the protected in situ nursery the longest were 3.9-5.6 times higher than corals transplanted to the reef earlier, demonstrating that an intermediate ocean nursery stage is critical in the sexual propagation of corals for reef rehabilitation. 3 years post-settlement, colonies were reproductively mature, making this one of few published studies to date to rear a broadcasting scleractinian from eggs to spawning adults. While our data show that it is technically feasible to transplant sexually propagated corals and rear them until maturity, producing a single 2.5year-old coral on the reef cost at least US $\$ 60$. 'What if' scenarios indicate that the cost per transplantable coral could be reduced by almost $80 \%$, nevertheless, it is likely that the high cost per coral using sexual propagation methods would constrain delivery of new corals to relatively small scales in many countries with coral reefs.

Keywords Coral reef - Reef rehabilitation . Larval rearing $\cdot$ Acropora $\cdot$ Philippines

Present Address:

M. V. Baria

Sesoko Station, Tropical Biosphere Research Center, University of the Ryukyus, 3422, Sesoko, Motobu, Okinawa 905-0227, Japan

\section{A. J. Heyward}

Australian Institute of Marine Science (AIMS), The University of Western Australia Oceans Institute, Perth, WA 6009, Australia 


\section{Introduction}

Active reef rehabilitation, although still in its infancy (Rinkevich 2005), has the potential to become a routine and increasingly used management tool. The aim of most reef rehabilitation efforts to date has been to reestablish coral cover on degraded reefs by transplanting artificially propagated corals. These can be produced asexually by culturing fragments removed from donor colonies or they can be produced sexually by collecting and rearing larvae or gametes from reproductively mature colonies (Rinkevich 1995; Petersen and Tollrian 2001). The former method has been practised for several decades (Alcala et al. 1982; Auberson 1982) and the techniques (at least in terms of rearing large numbers of asexual fragments) are now well established for many species and locations (Shafir et al. 2006). The latter method is still largely at an experimental stage both in terms of the optimal methods for rearing and settling larvae en masse and in terms of the best practices for transplantation to the reef (Guest et al. 2010).

Sexual coral propagation has both advantages and disadvantages when compared with asexual propagation methods. Sexual reproduction results in much greater genotypic diversity of transplanted corals; collateral damage to donor reefs is reduced because there is no need to fragment corals; and because corals are often highly fecund, sexual methods potentially provide access to millions of propagules. On the other hand, sexual methods are considerably more labour intensive; may require land based hatchery facilities and expertise in larval rearing techniques; and are likely to be more expensive than asexual techniques (Epstein et al. 2001).

In recent years, several advances have been made in techniques for sexually propagating broadcast spawning corals specifically for reef rehabilitation (Omori 2005; Okamoto et al. 2008; Guest et al. 2010; Nakamura et al. 2011). Typically, ceramic or terracotta tiles have been used as substrates for settlement of larvae, rearing and transplantation (e.g. Omori 2005; Nakamura et al. 2011), and this is undoubtedly a legacy of their use in coral larval recruitment studies (Mundy 2000). While square tiles are useful in experiments they are not very suitable as substrates for rearing corals for restoration because (a) it is difficult to control where coral spat settle, (b) tiles are not easy to handle without damaging settled spat, and (c) they do not have a device for specifically attaching them to the reef. Petersen et al. (2005) recognised this problem and devised ceramic coral settlement substrates specifically for rearing corals in aquaria. A logical extension of this is to have substrates designed specifically for transplantation of sexually propagated corals to the reef (Petersen and Tollrian 2001). Indeed, several such designs have been tested recently (Okamoto et al. 2008; Omori and Iwao 2009; Omori 2011; Boch and Morse 2012; Villanueva et al. 2012) and in each case, these substrates consist of an area for coral larvae to settle and a device specifically for attachment in a nursery or to the reef.

In the study presented here, we develop a coral settlement substrate, called the coral plug-in, which can be readily and cheaply replicated, used for rearing corals in nurseries and transplanted directly to reef substrata. Coral larvae of Acropora millepora were cultured in Bolinao, north-western Philippines and settled onto plug-ins, reared in ex situ and in situ nurseries before being transplanted to replicate experimental patches of reef within a marine protected area. To assess the feasibility of using this technique to restore coral cover to a degraded reef, we conducted an experiment to compare the effect of different nursery rearing times on survival and growth and to estimate the respective costs of producing a coral to a transplantable size and a 2.5-year-old coral transplant attached to the reef.

\section{Materials and methods}

\section{Coral settlement substrates}

All work including development of settlement substrates and coral larval rearing was carried out at the Bolinao Marine Laboratory (BML) in north-western Luzon, Philippines $\left(16^{\circ} 22^{\prime} \mathrm{N}, 119^{\circ} 54^{\prime} \mathrm{E}\right)$. An affordable substrate (the coral plug-in) was designed that could be used for settling coral larvae en masse, rearing the newly settled corals either ex situ in tanks or at an in situ field nursery, and attaching to the reef once corals had reached a suitable size. Each plug-in consisted of a plastic wall plug (size 10, width $10 \mathrm{~mm}$, length $50 \mathrm{~mm}$ ) for attachment to the reef and a cylindrical cement head (diameter $20 \mathrm{~mm}$, height $15 \mathrm{~mm}$, total surface area $1,492 \mathrm{~mm}^{2}$ ) (Fig. 1a) for larval settlement. To make the plug-ins, batches of cement at a ratio of 1 part river sand (300 mL cup or $450 \mathrm{~g}), 1$ part Portland cement $(300 \mathrm{~mL}$ cup or $420 \mathrm{~g})$ and water $(180 \mathrm{~mL})$ were mixed and placed in moulds made from sections of PVC pipe (20 $\mathrm{mm}$ diameter, $15 \mathrm{~mm}$ length). Wall plugs were inserted into the cement and left to dry for $24 \mathrm{~h}$ before the PVC mould was removed, after which the cement was washed once with fresh water and left to dry for a further $24 \mathrm{~h}$. Plug-ins were biologically conditioned in flowthrough seawater tanks containing pieces of crustose coralline algae (CCA), for at least 3 weeks prior to spawning to allow build up of a biofilm and suitable cues for coral settlement and metamorphosis (Heyward and Negri 1999). 
Larval culture

Acropora millepora spawns predominantly during March around Bolinao (Vicentuan et al. 2008). Eight gravid (i.e. containing large pigmented oocytes in fractured branches), $\sim 20 \mathrm{~cm}$ diameter colonies or colony fragments of $A$. millepora were collected between 20 and 25 March 2008 from two adjacent sites (Caniogan and Magsaysay, $16^{\circ} 19^{\prime} \mathrm{N}$ $120^{\circ} 01^{\prime} \mathrm{E}$ ) (the full moon was on 21 March 2008). Colonies were transported (approx. 1-h travel time) to BML in covered plastic bins filled with seawater where they were maintained in flow-through seawater tanks (400 L).

Each evening at $1700 \mathrm{~h}$ (approx. $1 \mathrm{~h}$ before sunset), colonies were isolated in $20 \mathrm{~L}$ buckets and monitored every $30 \mathrm{~min}$ until $2230 \mathrm{~h}$ or until spawning occurred, after which colonies were returned to flow-through seawater tanks. When spawning had finished, buoyant gamete bundles were scooped from the surface of buckets and transferred to a plastic fertilisation tank (50-60 L) containing UV-treated (Aquanetics Systems Inc., San Diego) 1- $\mu \mathrm{m}$ filtered seawater. Gamete bundles from the three colonies that spawned were mixed to allow cross-fertilisation and were stirred gently to separate eggs from sperm then left undisturbed for $1 \mathrm{~h}$ to fertilise. Water was siphoned from the bottom of the fertilisation tank onto a submerged $100-\mu \mathrm{m}$ mesh sieve to remove excess sperm water.
Embryos and oocytes trapped within the sieve were gently scooped and divided among two $60 \mathrm{~L}$ tanks containing clean filtered seawater. Rearing tanks were left static for at least $24 \mathrm{~h}$ after which mild aeration was introduced and subsequently $50 \%$ water changes were carried out once each day. Estimates of the number of propagules (eggs and larvae) were carried out at $1 \mathrm{~h}$ and 4 days post-spawning. This was done by stirring the tanks to evenly distribute propagules and taking a total of 24 samples $(2 \mathrm{~mL}$ for eggs and $10 \mathrm{~mL}$ for larvae).

The conditioned coral plug-ins were introduced to each tank 5 days after fertilisation. Plug-ins were inserted into pre-drilled holes on racks made from sections of $5 \mathrm{~cm}$ diameter PVC pipes (30 cm length). Each PVC pipe contained 40 plug-ins, and between 9 and 12 racks were suspended in each rearing tank (360-480 plug-ins per rearing tank). Plug-ins were left in the rearing tanks for 7 days to allow larvae to settle and deposit a skeleton (Fig. 1b), during which time aeration was continued and $100 \%$ water changes with sand filtered seawater were carried out daily. After 7 days, all racks were transferred to a larger tank ( $\sim 400 \mathrm{~L})$ with flow-through seawater, for ex situ rearing. Due to logistical constraints, it was not possible to carry out initial settlement counts; however, the number of visible corals settled on each plug-in was counted after 1 month of ex situ rearing.
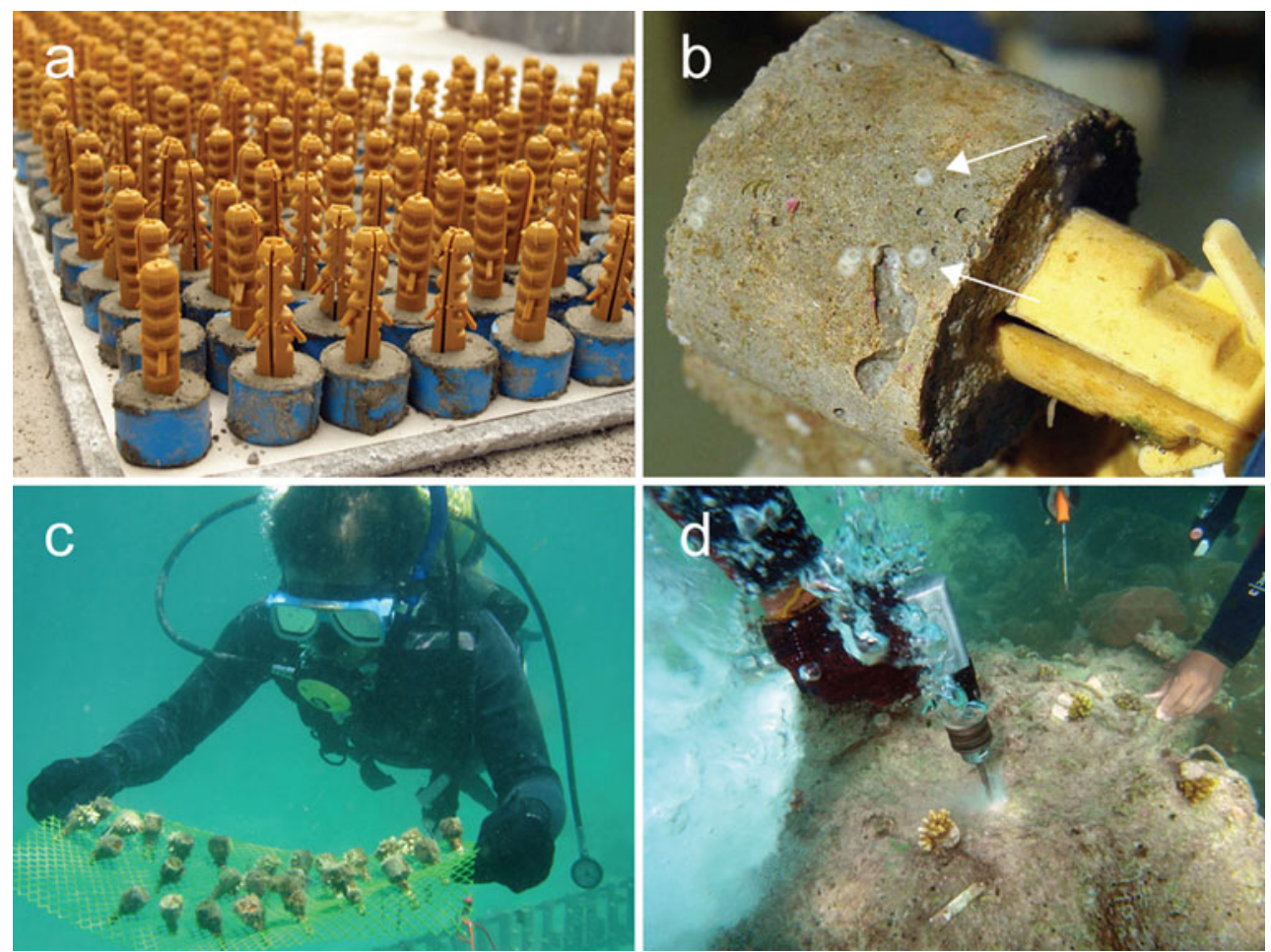

Fig. 1 a Newly constructed coral plug-ins still inside their PVC moulds; b recently settled A. millepora spat on head of a coral plug-in; $\mathbf{c}$ plugins being transported by a diver from the nursery to the reef; and $\mathbf{d}$ attaching plug-ins to the reef using a pneumatic drill 
Plug-ins that contained live corals were transferred in seawater filled, covered tubs to an in situ nursery located at a sheltered reef site at Malilnep channel $\left(16^{\circ} 26^{\prime} 08.2^{\prime \prime} \mathrm{N}\right.$, $119^{\circ} 56^{\prime} 29.2^{\prime \prime} \mathrm{E}$ ) in May 2008. The nursery was constructed of angle-iron bars (height $0.8 \mathrm{~m}$, width $0.6 \mathrm{~m}$, length $2.5 \mathrm{~m}$, depth of top of frame at low tide $1.8 \mathrm{~m}$ ) hammered into the underlying sand substrate at a low tide depth of $2.6 \mathrm{~m}$. Sections of PVC pipe containing corals were attached in a vertical orientation, and a sheet of PVC mesh (20 mm diameter) was attached to the top of the nursery to create an open-sided cage as this has been shown to increase post-settlement survival of Acropora spat (Baria et al. 2010).

Transplantation to the reef and monitoring of growth and survival

The number of surviving corals on plug-ins at the in situ nursery was counted approximately 7 months after spawning (17 October 2008), and the diameter of each surviving coral in the nursery was estimated. Coral size was estimated by calculating the geometric mean diameter (GMD) of each coral as follows:

$\mathrm{GMD}=\sqrt{D 1 \times D 2}$

where $D 1$ is the maximum diameter and $D 2$ the maximum perpendicular diameter. Coral plug-ins to be transplanted to the reef were haphazardly selected from the nursery and tagged with stainless steel labels, transferred to sheets of PVC mesh and transported by boat in covered seawater filled bins to the transplant site (approx. 20-min travel time) (Fig. 1c). Plug-ins with corals were transplanted onto three coral limestone outcrops on a fringing reef at Lucero marine protected area $\left(16^{\circ} 24^{\prime} 42.2^{\prime \prime} \mathrm{N}, 119^{\circ} 54^{\prime} 17^{\prime \prime} \mathrm{E}\right)$. Outcrops ranged in maximum diameter from 1.3 to $1.7 \mathrm{~m}$ and from 0.6 to $1.5 \mathrm{~m}$ in height above the substrate, and the water depth at the top of each outcrop ranged from 2.8 to $3.5 \mathrm{~m}$ at low tide. Holes were drilled at least $20 \mathrm{~cm}$ apart on the horizontal surfaces of each outcrop using a pneumatic drill with a size 10 drill bit, and an area around each hole was cleaned of sediments, algae and other fouling organisms prior to transplantation (Fig. 1d). The plastic plug of each plug-in was inserted fully into one of the holes with a small piece of epoxy putty (Pioneer Epoxyclay Aqua).

To examine differences in survival between transplanted corals that were reared at the in situ nursery for different periods of time, three separate batches of coral plug-ins with corals were transferred from the nursery to natural reef on 24 October $2008(n=60), 19$ May $2009(n=60)$ and 24 November $2009(n=30)$ approx. 7, 14 and 19 months after settlement (see Results section for sizes at time of transplantation for each batch) (Fig. 2). Hereafter, the three batches are referred to as the small, medium and large age/size classes of transplant. Bolinao is affected by the northeast (approx. Nov to Mar) and southwest monsoon seasons (approx. Jul to Sep). Corals were transplanted to the reef between monsoon seasons to coincide the field work with periods of calm weather. Sea surface temperature (SST) in Bolinao varies seasonally with mean monthly values ranging from $25^{\circ} \mathrm{C}$ in January to $30{ }^{\circ} \mathrm{C}$ in June (pers. obs.). The small and large age/size classes were transplanted just before the coolest months of the year, while the medium age/size class was outplanted just before the warmest months of the year.

Survival of nursery and transplanted corals was monitored approximately monthly from October 2008 throughout the study, except for gaps of 2-3 months between August and November 2009, March to May 2010 and a larger gap of 5 months between May and October 2010. To estimate growth rates, GMDs of transplanted corals were measured approximately every 6 months for the duration of the project. Some of the plug-ins contained more than one juvenile coral at the beginning of the transplantation study ( $n=39$ plugins), therefore the GMD of corals on these plug-ins was estimated based on the average GMD of all corals on the plug-in. As it was difficult to track survival of multiple individuals on a single substrate, a plug-in was considered dead for the purpose of the survival analysis when there were no surviving corals remaining on the plug-in.
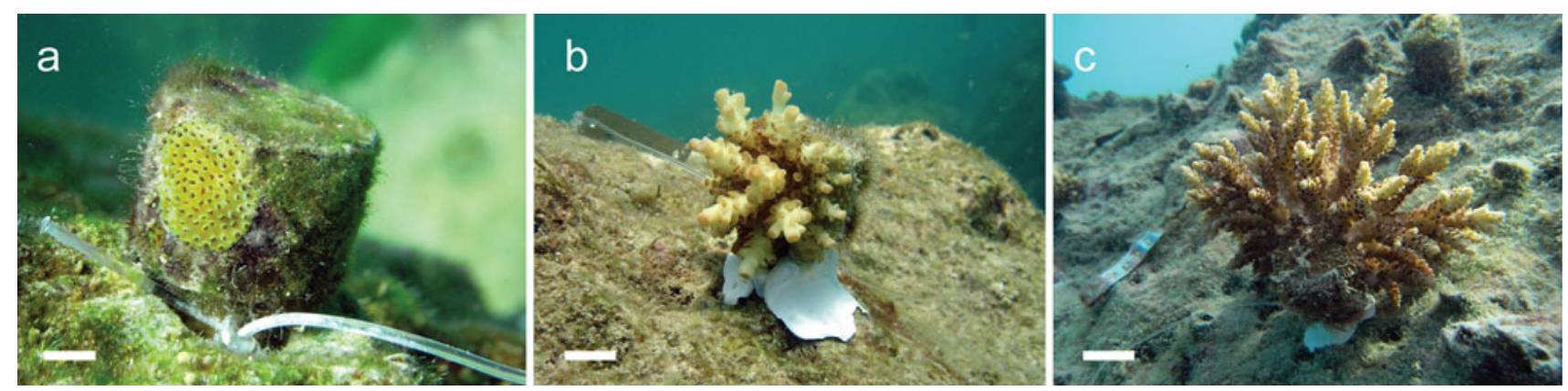

Fig. 2 Representative photos of the a small, b medium and c large age/size classes. Scale bars a $5 \mathrm{~mm}, \mathbf{b} 10 \mathrm{~mm}$ and $\mathbf{c} 20 \mathrm{~mm}$ 


\section{Costing exercise}

The methods for costing are described in detail by Edwards et al. (2010). The cost of equipment and consumables were separated from manpower costs, boat hire and scuba tank hire. Wage rates were based on standard local wage rates at the time the work was carried out in the Philippines between 2008 and 2010. Different wage rates were set depending on the skill-level required for each task as follows: level 1 (highest salary, e.g. scientific adviser/expert), US $\$ 5.63 \mathrm{~h}^{-1}$; level 2 (medium salary, e.g. trained local staff), US $\$ 3.50 \mathrm{~h}^{-1}$; and level 3 (lowest, e.g. trained manual labour), US\$1.31 $\mathrm{h}^{-1}$. Costs for capital equipment, i.e. equipment such as microscopes that could be used for longer than the duration of this project, were given a 3-year life span; therefore, the total capital equipment costs were divided by three. Cost of dive equipment was based on local rental costs of $\$ 20$ person $^{-1}$ day $^{-1}$ as the total cost of renting for this project was less than the cost of purchasing four full sets of diving equipment. Details of the costs of consumables, equipment and person hours are provided in the Electronic Supplementary Material (ESM Tables 1 and 2). Cost per coral was estimated by dividing the total cost for the project by the number of plug-ins containing one surviving coral for different production stages as follows: (1) a coral at the in situ nursery ready to be transplanted at 7, 14 and 19 months, (2) the cost of an outplanted juvenile for each age/size class and (3) the cost for a surviving 2.5year-old transplanted coral. By manipulating the pre- and post-transplantation survival rates of corals on plug-ins, we also calculated a "what if" scenario to estimate the cost per coral, assuming greater survival rates at different production stages. All costs were estimated in US dollars.

\section{Data analysis}

Kaplan-Meier product-limit analysis was used to estimate the shape of the curve of survival time for each of the transplant age/size classes (Lee and Wang 2003). Data were analysed using the distribution analysis (right censoring) tool in the reliability/survival library of Minitab (v. 14). As it was not possible to determine the exact time of death for each coral, the date that a coral died was estimated as the middle time point between survey dates. Survival functions of corals were compared (a) from the date of first outplant for each age/size class of transplant and (b) for approximately the first year after outplanting for each age/size class (13 months for the small and medium age/size class and 11 months large age/size class). To test for significant differences between survival curves for the three age/size classes during the year post-transplantation, pair-wise comparisons were performed using log rank and Wilcoxon's tests in Minitab (v. 14). Nonparametric
Kaplan-Meier analysis is not capable of incorporating replication; therefore, we also carried out separate KaplanMeier analyses to compare between age/size classes for each replicate outcrop. Two separate, one-way analyses of variance were carried out to test for differences in geometric mean diameters between all age/size classes of coral transplants to compare the size of corals at (a) the time of outplant for each age/size class and (b) the time of the final outplant in November 2011. Variances of the means for GMD were not homoscedastic even after transformation; therefore, parametric ANOVA was carried out on the untransformed data (Underwood 1997), followed by a Games-Howell post hoc test (Games and Howell 1976) as this is considered the most powerful test (i.e. least likely to result in a Type II error) when variances are not homogeneous.

\section{Results}

Larval culture and initial survival

Three colonies of A. millepora with geometric mean diameters of 188, 194 and $223 \mathrm{~mm}$ spawned on March 29 between 1900 and $2130 \mathrm{~h}$ releasing an estimated combined total of 120,000 eggs. On day 4 post-fertilisation, there were an estimated 102,500 motile larvae, indicating survival of $85.4 \%$ of initial spawned eggs. A total of 840 plug-ins were introduced to larva for settlement, at an approximate calculated density of 120 larvae per plug-in. Counts after 1 month revealed that there were 1,390 surviving coral spat on 531 plug-ins, of which 248 contained only one coral (the range was 1-41 corals per plug-in). This shows that $1.4 \%$ of the larvae available on day four had settled and survived for 1 month, with $63.3 \%$ of coral plug-ins supporting at least one surviving coral. After subsequent transfer and a further 6 months at the in situ nursery, 200 corals remained alive on 153 plug-ins, with 114 of the plug-ins containing a single coral (the range was 1-4 corals per plug-in). This represents $14.4 \%$ survival of coral spat between 1 and 7 months, with $29 \%$ of plug-ins transferred to the nursery still supporting at least one living coral.

Survivorship and growth rates of outplanted corals

Survival of corals at the in situ nursery was close to $100 \%$, with only 3 corals dying between 7 months of age and the last outplant at 19 months of age. Growth and survival of outplanted corals were monitored until approx. 24 months after the first transplantation or 31 months post-fertilisation. At the final survey (25 October 2010), 8.3 and $11.7 \%$ of the small and medium age/size transplants had survived, respectively, whereas $46.7 \%$ of the large age/size 
transplants survived (Fig. 3). Comparing just the first year's survival after transplantation for each size class, mean survival times for the small, medium and large size classes were 199.7, 191.1 and 291.9 days, respectively (Table 1). The largest class had significantly greater survival times than the small and medium classes; however, there were no significant differences between the small and medium age/size classes (Table 1). Separate analyses of each replicate outcrop showed the same hierarchy in each case with the larger age/size class surviving significantly longer than the small and medium age/size classes.

A notable increase in mortality for all age/size classes occurred during the 169 day period between the penultimate and the final monitoring occasions (9 May and 25 October 2010). During this period, there was a 13, 23 and $43 \%$ increase in mortality for the small, medium and large age/size classes, respectively (Fig. 3). This is equivalent to

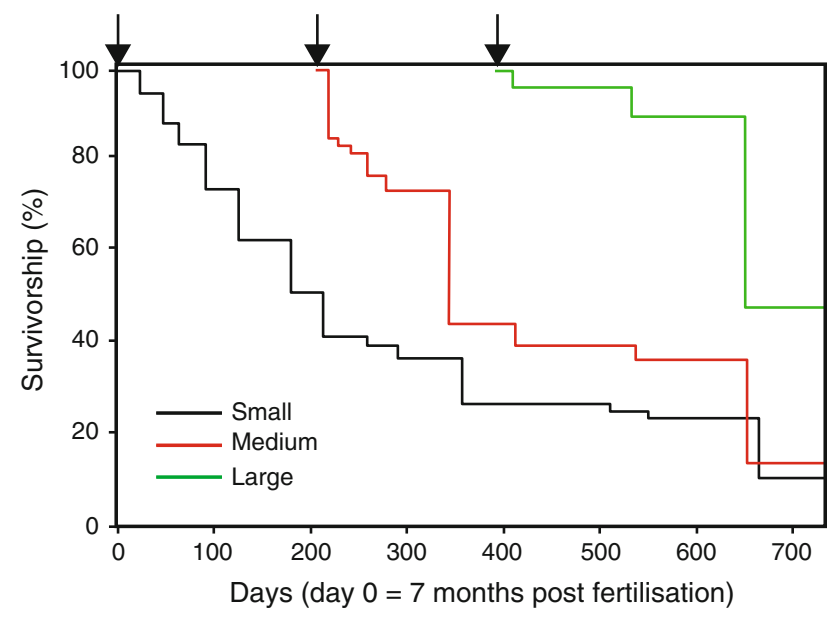

Fig. 3 Survival of each age/size class following transplantation to the reef over c. 2 year period from the date of the first outplant (day zero is c. 7 months post-fertilisation). Small age/size class black line, medium age/size class red line, large age/size class green line. Approx. time of each outplant indicated by arrow

Table 1 Statistical comparison of mean survival times for three age/ size classes of outplanted corals during the first 12 months posttransplantation

\begin{tabular}{|c|c|c|c|c|}
\hline $\begin{array}{l}\text { Size } \\
\text { class }\end{array}$ & $\begin{array}{l}\text { Mean survival time } \\
\text { (days) }\end{array}$ & $\begin{array}{l}\text { Lower } 95 \% \\
\text { CI }\end{array}$ & \multicolumn{2}{|c|}{$\begin{array}{l}\text { Upper } 95 \% \\
\text { CI }\end{array}$} \\
\hline Small & 199.7 & 167.4 & \multicolumn{2}{|c|}{231.9} \\
\hline Medium & 191.1 & 156.3 & \multicolumn{2}{|c|}{225.9} \\
\hline Large & 291.9 & 261.8 & \multicolumn{2}{|c|}{321.9} \\
\hline \multicolumn{2}{|l|}{ Method } & Chi square & $d f$ & $p$ \\
\hline \multicolumn{2}{|l|}{ Log rank } & 7.6 & 2 & 0.022 \\
\hline \multicolumn{2}{|l|}{ Wilcoxon } & 10.9 & 2 & 0.004 \\
\hline \multicolumn{5}{|c|}{ Large $>$ medium $=$ small } \\
\hline
\end{tabular}

a mortality rate of $2.41,4.21$ and $7.83 \%$ of corals per month. Comparing this to the previous 166 days, mortality was 3,8 and $10 \%$ for the respective age/size classes, or $0.60,1.50$ and $1.81 \%$ per month, a $2.7-4.3$ increase in mortality rate between the two periods.

The average GMD of all corals at the in situ nursery prior to the first outplant in October 2008 was $4.4 \mathrm{~mm}$ $(\mathrm{SD} \pm 2.3 \mathrm{~mm})$. After the first outplant, plug-ins remaining in the nursery $(n=90)$ contained corals with an average GMD of $4.20 \mathrm{~mm}(\mathrm{SD} \pm 2.1 \mathrm{~mm})$. At the time of outplant for each of the age/size classes, average GMDs ( \pm SD) were $5.0 \pm 2.8,23.1 \pm 6.0$ and $59.2 \pm 19.4 \mathrm{~mm}$, respectively, for the small, medium and large age/size classes (Fig. 4). GMDs were significantly different at the time of outplant for each age/size class $\left(F=322.7_{2,147,} p<0.0001\right)$, and a Games-Howell post hoc test showed significant differences between all age/size classes (Large $>$ Medium $>$ Small, $p<0.05$ ). When the final batch of $A$. millepora (i.e. the large age/size class) was outplanted in November 2009, the previously outplanted small and medium age/size classes had average GMDs of $26.9 \mathrm{~mm}(\mathrm{SD} \pm 9.7 \mathrm{~mm}$ ) and $31.2 \mathrm{~mm}$ (SD $\pm 5.7 \mathrm{~mm}$ ), respectively, approximately half the average GMD of the large age/size class (59.2 \pm SD $19.4 \mathrm{~mm})$ (Fig. 4). There was a significant difference between age size classes at the time of the last outplant $\left(F=35.1_{2,64}\right.$, $p<0.0001$ ), with the post hoc test showing that the large age/size class was significantly larger than the other age size classes $(p<0.05)$ (Large $>$ Medium $=$ Small). By the end of the experiment in October 2010, however, average GMDs among all size classes outplanted onto the reef were similar, ranging from 75.8 to $86.3 \mathrm{~mm}$. Between the time of the last outplant and the end of the experiment (19 and 31 months post-spawning), the rate of change in average GMD for the large age/size class $\left(2.3 \mathrm{~mm}\right.$ month $\left.^{-1}\right)$ was approx. half that of the small and medium age size classes (4.7 and $3.9 \mathrm{~mm} \mathrm{month}^{-1}$ ), indicating that the larger corals, once transplanted from the nursery had slower growth rates than corals that had previously been transplanted. The apparently slower growth rate of the large, relative to the smaller age/ size classes was due in part to a higher proportion of the corals from the large age/size classes shrinking after being transplanted. GMDs in a total of $19 \%$ of corals in the large age/size class became smaller following transplantation with an average reduction in GMD of $12.9 \mathrm{~mm} \mathrm{yr}^{-1}$ $\left(\mathrm{SD} \pm 7.0 \mathrm{~mm} \mathrm{yr}^{-1}\right)$. In contrast only one of each of the small and medium size/age class corals ( 9 and $5 \%$ respectively) became smaller, in each case by $2.1 \mathrm{~mm} \mathrm{yr}^{-1}$.

\section{Costs}

Costs for rearing a coral at the in situ nursery ranged from $\$ 19$ to $\$ 25$ depending on the amount of rearing time (i.e. from 7 to 19 months) (Table 2). As the same number of 
corals were transplanted in each hypothetical batch (150 plug-ins) regardless of size class, the cost of transplanting corals was constant at $\$ 4$ per coral. Based on the survival rates in this study, the cost per 2.5 year old coral ranged from $\$ 61$ for the corals reared at the in situ nursery for 19 months to $\$ 284$ for the corals reared at the in situ nursery for only 7 months, the lower cost of the former being due to higher survival rates (Table 2). Scenarios to scale up initial survival pre- and post-transplantation indicate that higher survival pre-transplant (i.e. during the ex situ and in situ nursery phase) could markedly reduce the cost per coral. For example, an increase in pre-transplantation survival to $50 \%$ would reduce the cost per transplanted coral to around US\$12 (Table 3). For a 2.5 year old transplanted coral, this scenario would result in a coral costing between US\$13 and US\$24 for post-transplantation survival rates of 90 and $50 \%$ respectively (Table 3).

\section{Discussion}

Large scale sexual propagation of corals for reef rehabilitation has been attempted on relatively few occasions (Omori et al. 2008; Nakamura et al. 2011). Here we demonstrate the effectiveness of a cheap and easy to make substrate designed specifically for settlement, nursery rearing, and subsequent outplant of sexually propagated corals. With the use of a simple in situ nursery we were able to rear corals to a transplantable size and to reproductive maturity in 3 years (reported in Baria et al. 2012).

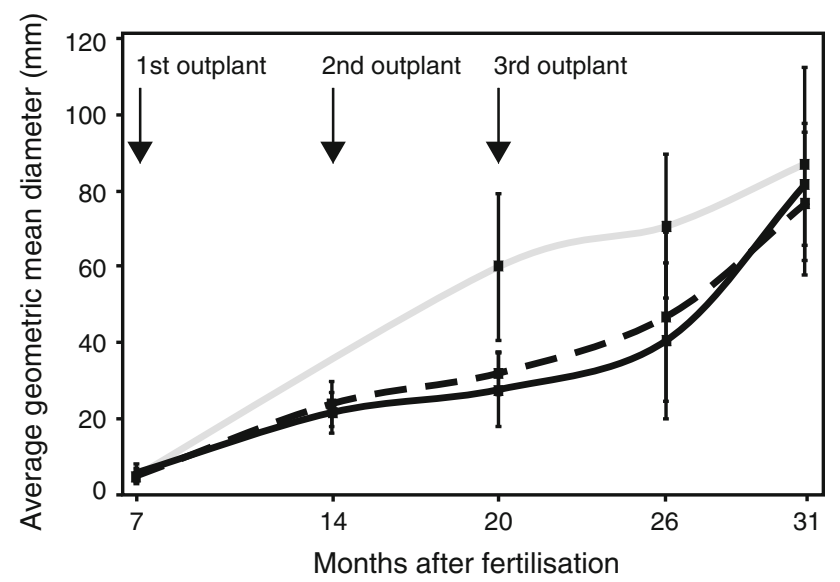

Fig. 4 Changes in average geometric mean diameters $(\mathrm{mm})$ of the small (outplanted October 2008), medium (outplanted May 2009) and large (outplanted November 2009) age/size classes over time, after transplantation to the reef (timing of outplants indicated by arrows). Error bars are $95 \%$ confidence intervals. Small age/size class black solid line, medium age/size class black broken line, large age/size class gray solid line
Larval rearing in the present study was successful with close to $85 \%$ of spawned eggs reaching settlement competency at day five post-spawning. After 1 month in an ex situ nursery $<1.5 \%$ of the larvae available on day 4 had settled and survived on coral plug-ins. Due to time constraints, counts of the number of initial settled spat were not carried out, so we do not know whether the relatively low proportion of live corals found after 1 month resulted from low initial settlement or from high levels of early post-settlement mortality. We have found with subsequent rearing efforts using plug-ins that it is possible to get settlement on $100 \%$ of substrates with potentially hundreds of larvae settling on a single substrate. It seems likely therefore that, in this case, the low proportion of corals that survived the initial nursery period was due to early postsettlement mortality. While the proportion of coral larvae settling and surviving during the first month was relatively low, almost two thirds ( $>63 \%$ ) of the plug-ins contained at least one live coral. This is important, because the unit for both propagation and eventual reef rehabilitation is a substrate containing at least one living coral, not the total number of living corals. After a further 6 months at an

Table 2 Cost of rearing corals on plug-ins to compare different rearing times in nursery based on survival rates obtained in present study

\begin{tabular}{llll}
\hline Age at outplant & 7 months & 14 months & 19 months \\
\hline Cost for juvenile in nursery & $\$ 19$ & $\$ 22$ & $\$ 25$ \\
$\begin{array}{l}\text { Cost per transplanted coral } \\
\text { Survival rate from outplant to }\end{array}$ & $\$ 2 \%$ & $\$ 26$ & $\$ 29$ \\
$\begin{array}{l}2.5 \text { years } \\
\begin{array}{l}\text { Cost per 2.5 year old } \\
\text { transplanted coral }\end{array}\end{array}$ & $\$ 284$ & $\$ 217$ & $\$ 61$ \\
\hline
\end{tabular}

Table 3 Costs per coral with improved survival rates both pre-and post-transplantation

\begin{tabular}{lllll}
\hline $\begin{array}{l}\text { Number of plug-ins } \\
\text { with } \geq 1 \text { coral } \\
\text { Survival }\end{array}$ & $\begin{array}{l}150 \text { Plug- } \\
\text { ins } \\
(18 \%)\end{array}$ & $\begin{array}{l}400 \text { Plug- } \\
\text { ins } \\
(50 \%)\end{array}$ & $\begin{array}{l}600 \text { Plug- } \\
\text { ins } \\
(70 \%)\end{array}$ & $\begin{array}{l}800 \text { Plug- } \\
\text { ins } \\
(95 \%)\end{array}$ \\
\hline $\begin{array}{l}\text { Cost per 19 month } \\
\text { coral at in situ } \\
\text { nursery }\end{array}$ & $\$ 24.92$ & $\$ 9.35$ & $\$ 6.55$ & $\$ 4.91$ \\
$\begin{array}{l}\text { Cost per } \\
\text { transplanted coral }\end{array}$ & $\$ 28.85$ & $\$ 12.01$ & $\$ 9.62$ & $\$ 7.21$ \\
$\begin{array}{l}\text { Costs for 2.5 year coral colony } \\
\text { Survival rate (\%) post-transplant }\end{array}$ & & & \\
90 & $\$ 32.06$ & $\$ 13.34$ & $\$ 9.77$ & $\$ 7.99$ \\
80 & $\$ 36.07$ & $\$ 15.01$ & $\$ 10.99$ & $\$ 8.99$ \\
70 & $\$ 41.02$ & $\$ 17.15$ & $\$ 12.57$ & $\$ 10.27$ \\
60 & $\$ 48.09$ & $\$ 20.01$ & $\$ 14.66$ & $\$ 11.98$ \\
50 & $\$ 57.71$ & $\$ 24.01$ & $\$ 17.59$ & $\$ 14.38$ \\
\hline
\end{tabular}


in situ nursery the number of plug-ins with corals had dropped to $29 \%$ of the initial plug-ins taken to the nursery. Between 7 months post-settlement and the time of the last outplant at 19 months, mortality rates for corals that remained in the nursery dropped to almost zero with only three corals dying during this period.

Clearly the biggest bottleneck for survival occurred during the first 7 months post-settlement. During the early life history stages, broadcast spawning corals are at their most vulnerable (Vermeij and Sandin 2008; Ritson-Williams et al. 2009). The most plausible explanation for an inverse relationship between mortality rate and colony size is that a disturbance event (for example a predator) is more likely to kill an entire colony if the surface area is small (Jackson 1979). Indeed, small corals can easily be removed in a single bite by a predator or accidentally by grazing herbivorous fish (Sammarco and Carleton 1981; Christiansen et al. 2009; Trapon et al. 2013). Furthermore, just after settlement broadcast spawning corals are likely to have limited energy reserves available to deal with competitive interactions from benthic organisms and for sediment removal (Rylaarsdam 1983; Vermeij 2006; Birrell et al. 2008; Ritson-Williams et al. 2009).

In the present study, corals were settled on surfaces that had a relatively undeveloped biofilm (see Fig. 1b) therefore spat would not have had to compete with benthic invertebrates and macroalgae immediately after settlement. During the 1 month ex situ rearing period however, in the absence of grazers, filamentous green algae developed in the rearing tanks and on the plug-ins. Therefore, while we cannot rule out the possibility that other factors (e.g. availability of zooxanthellae and planktonic food in the rearing tanks), played a role in early mortality during the ex situ rearing phase, we suggest that interactions with algae such as smothering, shading and allelopathy were the most likely cause (Birrell et al. 2008). In future efforts at the study site, this factor has been controlled relatively easily with the addition of small grazing molluscs (e.g. Trochus sp.) and this has been shown to improve early survival in other studies (Omori 2005).

More than $85 \%$ of the corals that were alive at the first census at 1 month had died by the end of the 6 month in situ nursery period. The exact causes of mortality during this period are unknown, however coral plug-ins were raised above the substrate and positioned vertically, therefore it is unlikely that sedimentation and benthic predators were major causes. The nursery was cleaned regularly, however it was not possible to manually remove fouling organisms from the plug-ins without damaging the corals, therefore, interactions with other fouling organisms (e.g. algae, sponges) growing on the plug-ins likely caused some of the mortality during this phase (Vermeij 2006). Schools of grazing fish were often seen visiting the nursery during monitoring occasions; it is possible therefore that some of the young corals were removed accidentally by fish during grazing. Fully caging newly settled corals to exclude grazing fish has been shown to improve survival of spat during the first few months after settlement (Baria et al. 2010). At some point, however, a trade off is likely to occur between mortality caused by grazing fish and that caused by competition with benthic algae (Birrell et al. 2008) thus cages would have to be removed once corals reach a suitable escape size.

In the present study, the density of spat on plug-ins ranged from 1 to 41 corals per plug-in after 1 month postsettlement, to 1-4 corals per plug-in at 7 months postsettlement. Initial settlement density on a single substratum, therefore may have influenced the probability of one coral surviving to a transplantable size on that substrate. On the one hand, if mortality of spat is independent of initial settlement density, then settling greater numbers of spat initially should increase the chances of a single coral surviving until transplantation. On the other hand, if mortality is density dependent, there may be an optimal starting settlement density for successful sexual propagation above or below which survival probability will diminish (Holm 1990).

Between 7 months post-settlement and the end of the study (31 months), mortality for corals remaining in the nursery was negligible. For corals transplanted to the reef however, mortality by the end of the study was considerably higher and significantly different for the three age/size classes of transplant (92 and $88 \%$ for the small, medium age/size classes versus $53 \%$ for the large age/size classes). While it is difficult to disentangle differences in mortality due to size and age from other causes related to the timing of outplant (e.g. temperature, seasonal storms), numerous other studies have shown mortality risk in corals to be strongly related to colony size, with smaller corals tending to be more vulnerable (Babcock 1991; Smith and Hughes 1999; Raymundo and Maypa 2004; Vermeij and Sandin 2008).

After 7 months, all individual corals were tracked over time to estimate survival times, however, due to the frequency of sampling, determining the actual cause of mortality after a coral had died was impossible in most cases. Corallivorous muricid snails (e.g. Drupella) were seen feeding on transplants on several monitoring occasions, suggesting that this was a significant cause of mortality. Between the penultimate and final monitoring occasions there was a marked increase in the rate of mortality for all age/size classes. Two major disturbances occurred during this period that could have accounted for this increase. A major thermal anomaly occurred between June and October 2010 when degree heating weeks (DHW) rose above $8{ }^{\circ} \mathrm{C}$ weeks for approximately 12 weeks (http:// 
coralreefwatch.noaa.gov/satellite/vs.php). Unfortunately, we were not able to return to the study site to monitor during this period, however anecdotal reports of coral bleaching of transplanted corals at nearby sites (R. Villanueva pers. comm.) suggest that temperature induced bleaching was in part responsible for the increase in mortality rate. In addition, a category 5 typhoon (Megi) passed close to the site on October 18, 2010. Many of the corals had begun to form branches by this time and thus would have been vulnerable to dislodgement by storms (due to a decrease in the size of attachment base relative to overall colony size) (Madin and Connolly 2006).

Corals that had remained in the nursery for longer were significantly larger than those that had been transplanted to the reef earlier (at 7 and 14 months). However, following transplantation to the reef, many of the corals from the final outplant tended to shrink. Therefore at the end of the monitoring ( $\sim 31$ months), average diameters were similar among the three age/size classes of transplants. Many of the larger, more extensively branched coral transplants were observed to have branch tips removed by fish, most likely by parrotfish, providing a possible explanation for the observed greater reduction in size of the larger size class of colonies following transplantation to the reef compared to the smaller age/size classes.

The detailed survival and growth monitoring was stopped after 2.5 years, however after 3 years a total of 12 corals transplanted to the reef and 19 corals remaining in the nursery (mostly growing on sections of PVC pipe) were checked for reproductive status (Baria et al. 2012). Coral colonies remaining in the nursery had GMDs ranging between 11.0 and $27.8 \mathrm{~cm}$ and a high proportion (almost $90 \%$ ) were gravid (i.e. containing pigmented oocytes). In contrast, corals that were sampled on the reef had GMDs ranging from 7.7 to $13.6 \mathrm{~cm}$ and only three out of twelve colonies $(25 \%)$ had pigmented oocytes.

Clearly the conditions for survival, growth and reproduction were better in the nursery than on the reef for this species. Corals in the nursery were raised above the substrate to reduce impacts from predation and sedimentation and the nursery was located in a lagoon protected from strong wave action. Corals on the reef on the other hand, were attached directly to the substrate at a site that experiences heavy wave action during the monsoon seasons. The most likely explanation for differences in the rates of mortality and growth is that predation and damage by storms was significantly reduced at the nursery site. These results highlight the importance of an intermediate nursery stage during coral propagation and the need for careful consideration of species choice and transplant location during restoration efforts.

The present study shows that the techniques for sexual propagation and transplantation of scleractinian corals are feasible and could be used to restore coral cover on areas of degraded reef at a local scale. Furthermore, some of the gravid colonies from the nursery were transferred to the hatchery facility where they spawned and the resulting larvae were settled onto new substrates for subsequent rearing (reported in Baria et al. 2012). This demonstrates the possibility of rearing corals from eggs to adults-thus closing the circle-and maintaining these adults as a broodstock for further spawning, removing the need for extracting colonies from the wild. The costing exercise however, demonstrated that rearing corals for reef rehabilitation using these techniques is likely to be a very expensive process, although costs varied considerably depending on the amount of time that corals were held in a nursery prior to transplantation. Survival after 2.5 years was considerably higher for the large age/size class (47\% survival) compared to that of the smaller age/size classes (12 and $8 \%$ survival). This difference resulted in a surviving 2.5 year old coral transplant that had been held in an in situ nursery for 19 months costing $\$ 61$, compared to corals that had been transplanted earlier (after 7 and 14 months) costing \$284 and \$217 respectively.

If we assume that our restoration goal was to attain at least one surviving 2.5 year old transplanted coral per square metre on a degraded reef, at a cost of $\$ 61$ per coral, restoration of one hectare of reef would require an investment of $>$ US $\$ 600,000$ in a developing country. These costs are prohibitive when we consider that the global average value, in terms of ecological goods and services, of one hectare of reef is estimated at approximately US $\$ 6,000 \mathrm{yr}^{-1}$ (Costanza et al. 1998). A simple extrapolation would suggest such a restored hectare of reef would need to persist and deliver equivalent ecological services for a century to recoup such an investment. The cost per coral is relatively high when compared to asexual propagation techniques (e.g. Levy et al. 2010), however it is in line with costs of other attempts to sexually propagate corals for reef rehabilitation. For example Nakamura et al. (2011) estimated costs of approx. US $\$ 163$ for a single substrate containing numerous 10 month old juvenile corals. Furthermore the estimated costs to restore a hectare of reef in this study are not atypical when compared to actual reef rehabilitation efforts. Examination of a range of previous case studies reveal costs ranging from tens of thousands to over a million US dollars per hectare with the median cost just below US $\$ 500,000 \mathrm{ha}^{-1}$ (Edwards et al. 2010).

Ongoing work at the study location suggests that costs of producing sexually propagated corals could be reduced. For example, in subsequent attempts at rearing corals on plug-ins we have achieved pre-transplantation survival of $>50 \%$ and post-transplantation survival of almost $90 \%$ during the first 12 months. At these survival rates a 2.5 year old transplanted coral would cost around US $\$ 13$, 
an almost $80 \%$ reduction in the cost per coral presented here (i.e. US\$61). Similarly, by improving early survival rates during the rearing phase and using a simplified plug design, a 12 month old transplanted colony of Acropora valida can be produced for approximately US\$11 (Villanueva et al. 2012). Furthermore, producing 5,000 plugins per year over a 3 year period would reduce the cost of a 2 year old transplanted coral to less than US\$5 due to economies of scale (Edwards et al. 2010). Nonetheless, in most countries with coral reefs, funds for environmental protection and conservation are limited and therefore coastal managers need to consider carefully if active rehabilitation techniques, such as those presented here, are a prudent use of limited funds. The relative costs and benefits of management measures (such as enforcement of protection and improving water quality) versus active rehabilitation (coral transplantation) should be examined carefully before embarking on a rehabilitation effort (Haisfield et al. 2010).

The results of this study show that it is a technically feasible, albeit expensive management option to restore cover on degraded reefs using sexually propagated corals. If survival rates are increased and/or production is scaled up to reduce costs, these techniques may be useful for rapidly increasing coral cover at relatively small scales on degraded reefs where there are suitable facilities and adequate funding. In addition, the techniques presented here could be combined with selective breeding programs that focus on rearing corals with specific traits, e.g. thermal tolerance, as a potential mitigation against climate change induced degradation of reefs.

Acknowledgments We thank Ronald de Guzman, Marcos Ponce, Romer Albino, Jun Castrence and all of the excellent staff at the Bolinao Marine Laboratory for their invaluable assistance. We are also grateful to four anonymous reviewers whose comments greatly improved the manuscript. This research was supported by the Global Environment Facility/World Bank funded Coral Reef Targeted Research for Capacity Building and Management program.

Open Access This article is distributed under the terms of the Creative Commons Attribution License which permits any use, distribution, and reproduction in any medium, provided the original author(s) and the source are credited.

\section{References}

Alcala AC, Gomez ED, Alcala LC (1982) Survival and growth of coral transplants in Central Philippines. Kalikasan 11:136-147

Auberson B (1982) Coral transplantation: an approach to the reestablishment of damaged reefs. Kalikasan 11:158-172

Babcock RC (1991) Comparative demography of three species of scleractinian corals using age-and size-dependent classifications. Ecol Monogr:225-244
Baria MV, Guest JR, Edwards AJ, Alino PM, Heyward AJ, Gomez ED (2010) Caging enhances post-settlement survival of juveniles of the scleractinian coral Acropora tenuis. J Exp Mar Biol Ecol 394:149-153

Baria MVB, Villanueva RD, Guest JR (2012) Spawning of threeyear-old Acropora millepora corals reared from larvae in northwestern Philippines. Bull Mar Sci 88:61-62

Birrell CL, McCook LJ, Willis BL, Diaz-Pulido GA (2008) Effects of benthic algae on the replenishment of corals and the implications for the resilience of coral reefs. Oceanogr Mar Biol Annu Rev 46:25-63

Boch CA, Morse ANC (2012) Testing the effectiveness of direct propagation techniques for coral restoration of Acropora spp. Ecol Eng 40:11-17

Christiansen NA, Ward S, Harii S, Tibbetts IR (2009) Grazing by a small fish affects the early stages of a post-settlement stony coral. Coral Reefs 28:47-51

Costanza R, d'Arge R, de Groot R, Farber S, Grasso M, Hannon B, Limburg K, Naeem S, O'Neill RV, Paruelo J (1998) The value of the world's ecosystem services and natural capital. Nature 387:253-260

Edwards A, Guest J, Rinkevich B, Omori M, Iwao K, Levy G, Shaish L (2010) Evaluating costs of restoration. In: Edwards A (ed) Reef rehabilitation manual. The Coral Reef Targeted Research \& Capacity Building for Management Program, St. Lucia, Australia, ii + p166

Epstein N, Bak RPM, Rinkevich B (2001) Strategies for gardening denuded coral reef areas: The applicability of using different types of coral material for reef restoration. Restor Ecol 9:432-442

Games PA, Howell JF (1976) Pairwise multiple comparison procedures with unequal n's and/or variances. J Edu Stat 1:113-125

Guest JR, Heyward A, Omori M, Iwao K, Morse ANC, Boch C (2010) Rearing coral larvae for reef rehabilitation. In: Edwards A (ed) Reef rehabilitation manual. The Coral Reef Targeted Research \& Capacity Building for Management Program, St. Lucia, Australia, ii + p166

Haisfield KM, Fox HE, Yen S, Mangubhai S, Mous PJ (2010) An ounce of prevention: cost-effectiveness of coral reef rehabilitation relative to enforcement. Conserv Lett 3:243-250

Heyward AJ, Negri AP (1999) Natural inducers for coral larval metamorphosis. Coral Reefs 18:273-279

Holm ER (1990) Effects of density-dependent mortality on the relationship between recruitment and larval settlement. Mar Ecol Prog Ser 60:141-146

Jackson JBC (1979) Morphological strategies of sessile animals. Rosen B, Larwood G (eds) Biology and systematics of colonial animals. Academic Press, New York, pp 499-555

Lee ET, Wang J (2003) Statistical methods for survival data analysis. Wiley-Interscience, New Jersey

Levy G, Shaish L, Haim A, Rinkevich B (2010) Mid-water rope nursery-Testing design and performance of a novel reef restoration instrument. Ecol Eng 36:560-569

Madin JS, Connolly SR (2006) Ecological consequences of major hydrodynamic disturbances on coral reefs. Nature 444:477-480

Mundy CN (2000) An appraisal of methods used in coral recruitment studies. Coral Reefs 19:124-131

Nakamura R, Ando W, Yamamoto H, Kitano M, Sato A, Nakamura M, Kayanne H, Omori M (2011) Corals mass-cultured from eggs and transplanted as juveniles to their native, remote coral reef. Mar Ecol Prog Ser 436:161-168

Okamoto M, Nojima S, Fujiwara S, Furushima Y (2008) Development of ceramic settlement devices for coral reef restoration using in situ sexual reproduction of corals. Fish Sci $74: 1245-1253$ 
Omori M (2005) Success of mass culture of Acropora corals from egg to colony in open water. Coral Reefs $24: 563-563$

Omori M (2011) Degradation and restoration of coral reefs: Experience in Okinawa, Japan. Mar Biol Res 7:3-12

Omori M, Iwao K (2009) A novel substrate (the "coral peg") for deploying sexually propagated corals for reef restoration. Galaxea 11:39-39

Omori M, Iwao K, Tamura M (2008) Growth of transplanted Acropora tenuis 2 years after egg culture. Coral Reefs 27:165-165

Petersen D, Tollrian R (2001) Methods to enhance sexual recruitment for restoration of damaged reefs. Bull Mar Sci 69:989-1000

Petersen D, Laterveer M, Schuhmacher H (2005) Innovative substrate tiles to spatially control larval settlement in coral culture. Mar Biol 146:937-942

Raymundo LJ, Maypa AP (2004) Getting bigger faster: mediation of size-specific mortality via fusion in juvenile coral transplants. Ecol Appl 14:281-295

Rinkevich B (1995) Restoration strategies for coral reefs damaged by recreational activities: The use of sexual and asexual recruits. Restor Ecol 3:241-251

Rinkevich B (2005) Conservation of coral reefs through active restoration measures: Recent approaches and last decade progress. Environ Sci Technol 39:4333-4342

Ritson-Williams R, Arnold SN, Fogarty ND, Steneck RS, Vermeij MJ, Paul VJ (2009) New perspectives on ecological mechanisms affecting coral recruitment on reefs. Smithson Contrib Mar Sci 38:437-457

Rylaarsdam KW (1983) Life histories and abundance patterns of colonial corals on Jamaican reefs. Mar Ecol Prog Ser 13:249-260
Sammarco PP, Carleton JJ (1981) Damselfish territoriality and coral community structure: reduced grazing, coral recruitment, and effects on coral spat. Proc $4^{\text {th }}$ Int Coral Reef Symp 2: 525-535

Shafir S, Van Rijn J, Rinkevich B (2006) Steps in the construction of underwater coral nursery, an essential component in reef restoration acts. Mar Biol 149:679-687

Smith LD, Hughes TP (1999) An experimental assessment of survival, re-attachment and fecundity of coral fragments. J Exp Mar Biol Ecol 235:147-164

Trapon ML, Pratchett MS, Hoey AS, Baird AH (2013) Influence of fish grazing and sedimentation on the early post-settlement survival of the tabular coral Acropora cytherea. Coral Reefs 32:1051-1059

Underwood AJ (1997) Experiments in ecology. Cambridge University Press, Cambridge

Vermeij MJA (2006) Early life-history dynamics of Caribbean coral species on artificial substratum: the importance of competition, growth and variation in life-history strategy. Coral Reefs 25:59-71

Vermeij MJA, Sandin SA (2008) Density-dependent settlement and mortality structure the earliest life phases of a coral population. Ecology 89:1994-2004

Vicentuan KC, Guest JR, Baria MV, Cabaitan PC, Dizon RM, Villanueva RD, Alino PM, Gomez ED, Edwards AJ, Heyward AJ (2008) Multi-species spawning of corals in north-western Philippines. Coral Reefs 27:83-83

Villanueva RD, Baria MVB, dela Cruz DW (2012) Growth and survivorship of juvenile corals outplanted to degraded reef areas in Bolinao-Anda Reef Complex, Philippines. Mar Biol Res 8:877-884 